\title{
Clinical Significance of Some Tumour Biomarkers in the Diagnosis of Breast Cancer in Comparison with Histopathological Biopsy
}

\author{
Adil Nadhim Radhi ${ }^{1}$, Mahdi Murshd Thuwaini ${ }^{2}$, Hamed Jaddoa Abbas ${ }^{3}$

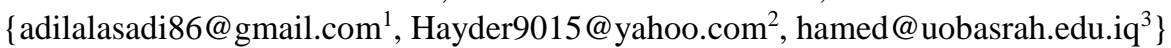 \\ College of Medical and Health Technology / Southern Technical University - Basrah, Iraq ${ }^{1,2}$ \\ Al-Fayhaa Teaching Hospital - Al- Zahraa Medical college- Basrah University, Basrah, Iraq ${ }^{3}$
}

\begin{abstract}
This study aimed to assess the diagnostic power of tumour biomarkers (Serum CA15-3, CA27.29, and CA549) in the diagnosis or confirming the breast cancer (BC) in comparison with histopathological biopsy. A case-control study consisted of (60) female patients with breast cancer and (30) healthy subjects as control. Kits were used to measure serum CA15-3, while Enzyme-Linked Immunosorbent Assay (ELISA) was used to measure Serum CA27.29 and CA549. The current study showed that there were highly significant increases in the levels of CA15-3, CA27-29 with BC cases. It was also a highly significant increase in the levels of CA15-3, CA27-29, in BC patients with stage IV compared to another state. The study also showed that the sensitivity values of the markers were: $87 \%$, $36 \%, 56 \%$ for the markers CA15-3, CA27-29, and CA 549 respectively. The study also reveals that specificity values of the markers were: $62 \%, 36 \%, 40 \%$ for the same markers respectively. It could be concluded these markers could be used in the diagnosis of BC.
\end{abstract}

Keywords: BC, Tumour Markers, CA 15-3, CA 27.29, CA 549

\section{Introduction}

Breast cancer is the most common cancer in women of all ages, including those under 35 years old, and it continues to be the leading cause of cancer-related death. Women under the age of 50 are not screened, therefore cancer diagnosis is made based on clinical signs and symptoms, which can be inconvenient and postponed [1].

$\mathrm{BC}$ is a worldwide health problem; it is the leading for death among females allover the world and too expensive to treat. Because health-care assets are limited, decisions about BC treatments are made on "value for money" [2].

Invasive breast cancer incidence is steadily rising since 2004. According to a recent study, rises in body mass index (BMI) and decreases in the average number of births per woman (both BC risk factors) have recently contributed to rise in incidence. In 2017, an estimated 231,840 women in the USA would be detected with BC. This is also the $2^{\text {nd }}$ largest reason of death in women, after lung cancer [3]. It causes early mortality in females. When a tumour is tiny and treatable, breast cancer usually has no symptoms, which is why screening is critical for early identification.. A painless lump is the most prevalent physical indication. Even before the primary breast tumour, breast cancer can migrate to underarm lymph nodes and generate a lump 
or swelling [4]. Early detection, determining prognosis, predicting response or hard to treat medicines, surveillance following primary surgery, and monitoring therapy with all possible uses of markers serum in BC [4]. The major goal of this study was to compare the rate of diagnostic of tumour biomarkers (Serum CA 15-3, CA 27.29, and CA 549) with histopathological biopsy in diagnosing primary breast cancer.

\section{Materials and Methods}

60 women was considered and diagnosed with breast cancer. In the study, population age ranged from (30-74 years) old. The study also included (30) healthy women as control. Who visited Al-Basra Oncology Centre in Al-Sadr Teaching Hospital in Basra? All patients in this research were diagnosed by oncologist Al-Basra Oncology Centre in Al-Basra Teaching Hospital and confirmed by all clinical and laboratory investigations throughout the period from October 2020 to May 2020. The practical analyses of the study were carried out in the department of Medical Laboratory at STU, Basra. Kits were used to measure serum CA 15-3 (Roche Diagnostics- Switzerland), while Enzyme-Linked Immunosorbent Assay (ELISA) was applied to measure Serum CA 27.29 and CA 549

\subsection{Statistical Analysis}

Mean and variance (SD) of the data were computed. The t-test (for means) and the chi-square test were used to see if there were any differences between the groups (for frequencies). SPSS for Windows was used to conduct all statistical analyses (version 23, USA). ANOVA was employed for normally distributed data. Example is when $\mathrm{P}<0.05$ was statistically considered significant, while $\mathrm{P}>0.05$ was judged non-significant.

\section{Results and Discussion}

\subsection{Features of the Groups suggested}

Table 1. showed statistical distribution (frequency and percentage) of study groups (patients and control) by their age and breast cancer characteristics. This table explained that the highest percentage of the age subgroup is (41-51) years which constituted (50\%) for the patient's group, and $(5.7 \%)$ for the control group. This same table revealed that the highest percentage of patient's subgroup are those with Grade II (62.2\%), Stage II (68\%).

Table 1. Statistical distribution (frequency and percentage) of study groups (patients and control) by their age and breast cancer characteristics.

\begin{tabular}{|c|c|c|c|c|c|c|}
\hline \multirow{2}{*}{ Items } & \multirow{2}{*}{$\begin{array}{l}\text { Sub- } \\
\text { groups }\end{array}$} & \multicolumn{2}{|c|}{$\begin{array}{l}\text { BC Patients } \\
\quad(\mathrm{N}=60)\end{array}$} & \multicolumn{2}{|c|}{$\begin{array}{l}\text { Control Group } \\
\quad(\mathrm{N}=30)\end{array}$} & \multirow{2}{*}{$\begin{array}{c}\text { Chi Square } \\
\text { (P value) } \\
\text { Sig. }\end{array}$} \\
\hline & & Freq. & $\%$ & $\begin{array}{c}\text { Fre } \\
\text { q. }\end{array}$ & $\%$ & \\
\hline \multirow{3}{*}{ Age } & $30-40$ & 11 & 18.3 & 4 & 13.3 & \multirow{3}{*}{$\begin{array}{c}2.05 \\
(0.56) \\
\text { NS }\end{array}$} \\
\hline & $41-51$ & 30 & 50.0 & 17 & 56.7 & \\
\hline & $52-62$ & 16 & 26.7 & 9 & 30.0 & \\
\hline
\end{tabular}




\begin{tabular}{|c|c|c|c|c|c|c|}
\hline & $63-73$ & 3 & 5.0 & 0 & 0.0 & \\
\hline \multirow{4}{*}{ Grade } & I & 0 & 0.0 & - & - & \multirow{4}{*}{ - } \\
\hline & II & 37 & 62.2 & - & - & \\
\hline & III & 23 & 37.8 & - & - & \\
\hline & IV & 0 & 0.0 & - & - & \\
\hline \multirow{4}{*}{ Stage } & I & 0 & 0.0 & - & - & \multirow{4}{*}{ - } \\
\hline & II & 45 & 75.6 & - & - & \\
\hline & III & 12 & 20.0 & - & - & \\
\hline & IV & 3 & 4.4 & - & - & \\
\hline
\end{tabular}

NS: at P value>0.05; SD: Stand. Dev.

\subsection{Measurement of Biomarkers}

Table 2. Differences in the measurement of serum biomarkers between BC patients and control group.

\begin{tabular}{|c|c|c|c|c|c|}
\hline \multirow{2}{*}{ Biomarkers } & \multicolumn{2}{|c|}{$\begin{array}{c}\text { BC Patients } \\
(\mathrm{N}=60)\end{array}$} & \multicolumn{2}{c|}{$\begin{array}{c}\text { Control Group } \\
(\mathrm{N}=30)\end{array}$} & \multirow{2}{*}{$\begin{array}{c}\text { T Test } \\
\text { P value }\end{array}$} \\
\cline { 2 - 5 } & Mean & SD & Mean & SD & \\
\hline CA 15-3 & 130.19 & 66.2 & 6.83 & 1.61 & $\begin{array}{c}4.58 \\
0.000(\mathrm{HS})\end{array}$ \\
\hline CA 27-29 & 10.89 & 9.58 & 6.09 & 1.89 & $\begin{array}{c}3.69 \\
0.000(\mathrm{HS})\end{array}$ \\
\hline CA 549 & 0.22 & 0.05 & 0.20 & 0.04 & $\begin{array}{c}1.21 \\
0.22(\mathrm{NS})\end{array}$ \\
\hline
\end{tabular}

HS: at $\mathrm{P} \leq 0.01$; NS: at $\mathrm{P} \leq 0.05$; SD: Stan. Dev.

Table 2. exhibited differences in the measurement of serum biomarkers between BC patients and the control group. This table shows that there is a highly significant increase ( $\mathrm{P}$-value < $0.01)$ in the levels in BC patients compared to the control group for the biomarkers: CA 15-3 and CA 27-29.

\subsection{Measurement of Biomarkers During Different Stages of Breast Cancer}

Table 3. ANOVA table for Differences in the measurement of biomarkers among various states of BC.

\begin{tabular}{|l|c|c|c|c|}
\hline \multirow{2}{*}{ Biomarkers } & \multicolumn{3}{|c|}{ Stage Sub-groups } & \multirow{2}{*}{ F Test } \\
\cline { 2 - 4 } & $\begin{array}{c}\text { Stage } 2 \\
(\mathrm{~N}=68)\end{array}$ & $\begin{array}{c}\text { Sage3 } \\
(\mathrm{N}=18)\end{array}$ & $\begin{array}{c}\text { Stage4 } \\
(\mathrm{N}=4)\end{array}$ & P-value \\
\hline
\end{tabular}




\begin{tabular}{|c|c|c|c|c|c|}
\hline \multirow{2}{*}{ CA 15-3 } & Mean & $99.05 \mathrm{~A}$ & $58.94 \mathrm{~A}$ & $157.00 \mathrm{~B}$ & 10.92 \\
\cline { 2 - 5 } & SD & 127.81 & 55.78 & 20.38 & $0.000(\mathrm{HS})$ \\
\hline \multirow{2}{*}{ CA 27-29 } & Mean & $9.48 \mathrm{~A}$ & $13.59 \mathrm{~A}$ & $22.88 \mathrm{~B}$ & 3.10 \\
\cline { 2 - 5 } & SD & 10.27 & 14.91 & 17.97 & $0.05(\mathrm{~S})$ \\
\hline \multirow{2}{*}{ CA 549 } & Mean & 0.21 & 0.23 & 0.23 & 0.66 \\
\cline { 2 - 5 } & SD & 0.05 & 0.03 & 0.05 & $0.52(\mathrm{NS})$ \\
\hline
\end{tabular}

HS: at $\mathrm{P} \leq 0.01$; SS at $\mathrm{P} \leq 0.05$; NS: at $\mathrm{P}>0.05$; SD: Standard Deviation; ANOVA: Analysis of Variance; Different letters refer to the significant difference among stages.

Table 3. revealed differences in the measurement of biomarkers among patients' subgroups classified according to the stage of breast cancer. This table showed that there is a highly significant increase (P-value < 0.01) in the levels of CA 15-3 and CA 27-29 in BC non-control with stage IV as compared to stage II and stage III.

\subsection{Receiver-operating characteristics of the Biomarkers}

Table 4. ROC and AUC of the biomarkers for the detection of BC. AUC: Area Under the curve; Positive Predictive Value (PPV); Negative Predictive Value (NPV).

\begin{tabular}{|c|c|c|c|c|c|c|c|}
\hline Biomarkers & (AUC) & $\begin{array}{c}\text { Sig. } \\
\text { p-value }\end{array}$ & $\begin{array}{c}\text { Cut-off } \\
\text { Point }\end{array}$ & $\begin{array}{c}\text { Sensitivit } \\
\mathrm{y}(\%)\end{array}$ & $\begin{array}{c}\text { Specificit } \\
\mathrm{y}(\%)\end{array}$ & PPV & NPV \\
\hline CA 15-3 & 0.83 & 0.000 & 6.33 & 0.87 & 0.62 & 0.82 & 0.72 \\
\hline CA 27-29 & 0.51 & 0.81 & 6.1 & 0.36 & 0.36 & 0.53 & 0.21 \\
\hline CA 549 & 0.58 & 0.15 & 0.20 & 0.56 & 0.40 & 0.65 & 0.30 \\
\hline
\end{tabular}

Figure 1 and Table 4 It was about biomarker full area (is well AUC) and (ROC) curve examination for breast cancer diagnosis. The sensitivity values for the markers CA 15-3, CA 27-29, and CA 549 were $0.87 \%, 0.36 \%$, and $0.56 \%$, respectively, as shown in the table. The same table revealed that sensitivity values of the markers were: $62 \%, 36 \%$, and $40 \%$ for the same markers respectively.
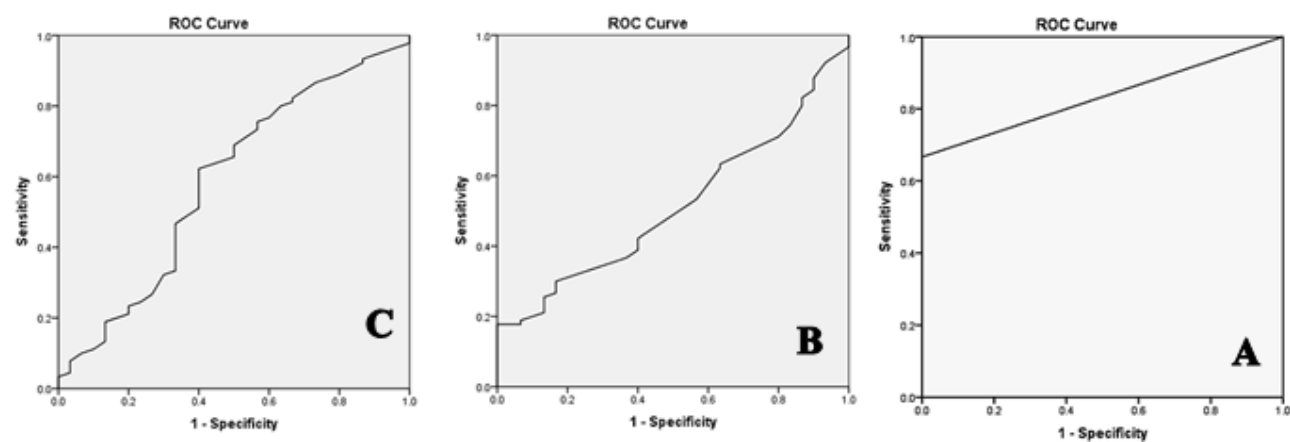

Fig 1. Diagonal segment of the ROC curve for (A) : CA 15-3 (B) : CA 27-29 (C) : CA549

Regarding CA-15-3, the results agreed with, the current study agrees with Hussain et al., they showed a highly significant elevation (mean value $=35.450 \mathrm{U} / \mathrm{ml}$ ) in Ca15-3 serum levels in $\mathrm{BC}$ patients in comparison with the control group (mean value $=8.180 \mathrm{U} / \mathrm{ml}$ ) and this increasing 
due to increased secretion of Ca15 - 3 from cancer cells [6]. This result also come in agreement with Hassan et al. that showed increased CA 15-3 in BC patients. Previous research revealed the tumour marker CA $15-3$ is the most commonly used tumor-tagging the suitable diagnosis and clinical practise of BC patients' monitoring and follow-up [7]. It was also suggested that elevated levels of the tumour marker with 1\% CA 15-detection rate of control and 3\%: -20\% of benign breast changes, $36 \%$ : $-40 \%$ of hepatitis, and 14 percent -70 percent of gastric cancer patients. CA15-13 appears to play a role in the malignancy of breast cancer, as it was discovered that CA15-3 has significantly elevated serum levels but not with benign tumours; in addition, $\mathrm{Fu}$ and Li discovered that malignant tumours all over the stages had high CA15-3, especially in advanced stages [9].

The current study's findings concurred with Atom et al., who observed substantial changes in in the level of CA15-3 of various stages of BC [10], but differed from Moazzezy et al., who discovered that serm level of CA15-3 and CEA were unrelated to BC staging [11]. CA15-3 is significantly correlated with $\mathrm{BC}$ in all stages (Stage I: SMD $=2.03$, Stage II: SMD=3.88, Stage III: SMD=5.12), according to a large meta-analysis conducted by Zhang et al. While all malignant tumours have elevated levels of CA15-3, it was discovered that the level of CA15-3 keeps rising tumour progresses. These findings show that monitoring CA15-3 levels rather than early diagnosis may be more effective for monitoring advanced tumours [2]. CA15-3 is a mucinous glycoprotein that is one of the Mucin1 (MUC-1) gene's products. MUC-1 is frequently linked to malignancies of the colon, breast, ovary, lung, and pancreas. The levels of CA15-3 and CEA in the blood were found to be strongly linked with the chance of developing malignant breast cancer in a meta-analysis research [9].

In the case of CA 27-29, the findings of this study agree with Chan et al., the authors of a previous study. An immunoradiometric technique was used to analyse 1721 patients with benign and malignant breast cancer in a multicentre investigation of CA549, a breast cancer marker. A 95 percent combined specificity was achieved. The specificity for benign breast disorders was 94.8 percent, and 88.2 percent for other benign diseases, for a total of 90.1 percent. The combined specificity for patients with malignant (non-breast) disorders was 75.6 percent; the findings correspond with Kabel (2017), who discovered the MUC-1 gene. CA 27.29 is strongly linked to breast cancer, with an elevated CA 27.29 level found in $80 \%$ of women with breast cancer. CA 27-29, on the other hand, can be discovered in patients with various cancers, as well as benign breast, liver, and kidney problems, and ovarian cysts. [12].

According to preliminary study, each signal has limited sensitivity and specificity in detecting early metastatic disease following breast cancer surgery [13]. Regarding CA 15-3, which is the most commonly used tumour marker in the diagnosis of breast cancer, Zaleski et al. investigated improved sensitivity for breast cancer detection using a combination of miR-34a and tumour markers CA 15-3 or CEA, and discovered that the AUC, sensitivity, and specificity for CA 153 were $0.72,0.95$, and 0.36 , respectively [14]. CA15.3 is the most commonly utilised breast tumour marker, according to a recent study this is not applicable and prognosis in individuals who have already been diagnosed [3].

\section{Conclusion}

The researchers discovered that patients with breast cancer had higher levels of the following biomarkers: CA 15-3, CA 27-29. CA 15-3 and CA 27-29 are two biomarkers that have increased in correlation with advanced stages of breast cancer. In the diagnosis of breast cancer, CA 15-3 had a good sensitivity and specificity. 


\section{References}

[1] Seidler S. J. and Huber D.E. Overview of Diagnosis and Treatment of Breast Cancer in Young Women. EC Gynaecology, 2020, SI.02: 18-25.

[2] Zhang X, Xing C, Guan W, Chen L, Guo K, Yu A, Xie K. Clinicopathological and prognostic significance of nestin expression in patients with breast cancer: a systematic review and metaanalysis. Cancer Cell Int. 2020, 14;20:169.

[3] Aglan, S. A., Elsammak, M., Elsammak, O., El-Bakoury, E. A., Elsheredy, H. G., Ahmed, Y. S., Sultan, M. H., \& Awad, A. M. (2021). Evaluation of serum Nestin and HOTAIR rs12826786 C>T polymorphism as screening tools for breast cancer in Egyptian women. Journal of medical biochemistry, 2020, 40(1), 17-25.

[4] Wolff AC, Tung NM, Carey LA. Implications of Neoadjuvant Therapy in Human Epidermal Growth Factor Receptor 2-Positive Breast Cancer. J Clin Oncol. 2019, 2019;3.

[5] Li J, Guan X, Fan Z, Ching LM, Li Y, Wang X, Cao WM, Liu DX. Non-Invasive Biomarkers for Early Detection of Breast Cancer. Cancers (Basel). 2020 ,12(10):2767.

[6] Hussain A. M., Ali H. A. and Mohammed H. L. The Ca 15-3, Ca 27.29 And Amh Biomarkers For Breast Cancer In Iraqi Patients . Biochemical And Cellular Archives, 2020, .20 : 1119.

[7] Hassan H. AB-H, Tauma A. M. and Ataimish SH. H. Determination of Some Biochemical Markers for Breast Cancer Women in Baghdad. AL - Ma'mon Collage J., 2016, 1 (28), 317 - 327.

Kabel, A. M. Tumor markers of breast cancer : New prospectives . Journal of Oncological Sciences., 2017, $3: 5-11$.

[8] Laessing D, Nagel D, Heinemann V, Untch M, Kahlert S, Bauerfeind I. Importance of CEA and CA 15-3 during disease progression in metastatic breast cancer patients. Anticancer Res., 2017,27 (4A): $1963-8$.

[9] Fu Y, Li H. (2016) Assessing Clinical Significance of Serum CA15-3 and Carcinoembryonic Antigen (CEA) Levels in Breast Cancer Patients: A Meta-Analysis. Med Sci Monit. 2016; 22:3154-3162 .

[10] Atoum M, Nimer N, Abdeldayem S, Nasr H. Relationships among Serum CA15-3 tumor marker, TNM staging, and estrogen and progesterone receptor expression in benign and malignant breast lesions. Asian Pac J Cancer Prev, 2012, 13(3): 857-60 .

[11] Moazzezy N, Farahany TZ, Oloomi M, Bouzari S. Relationship between pre 7 operative serum CA 15-3 and CEA levels and clinicopathological parame 7 ters in breast cancer. Asian Pac J Cancer Prev, 2014, 15(4): 1685-88 .

[12] Chan, D. W., Beveridge, R. A., Bhargava A., Wilcox, P. M. Kennedy, J. Schwartz, M. K. Breast Cancer Marker CA549: A Multicenter Study . American Journal of Clinical Pathology, 1994, 101(4) :465-470

[13] Nicolini A, Carpi A, Ferrari P, Morganti R, Mazzotti V, Barak V, Duffy MJ. An individual reference limit of the serum CEA-TPA-CA 15-3 tumor marker panel in the surveillance of asymptomatic women following surgery for primary breast cancer. Cancer Manag Res., 2018, 10:6879-6886 .

[14] Zaleski, M., Kobilay, M., Schroeder, L., Debald, M., Semaan, A., Hettwer, K., Uhlig, S., Kuhn, W., Hartmann, G., \& Holdenrieder, S. (2018). Improved sensitivity for detection of breast cancer by combination of miR-34a and tumor markers CA 15-3 or CEA. Oncotarget, 9(32), 22523-22536. 